\title{
Unusual dermatomycoses caused by Nannizzia nana: the geophilic origin of human infections
}

\author{
Sebastian Gnat ${ }^{1} \cdot$ Dominik Łagowski $^{1}$. Aneta Nowakiewicz ${ }^{1} \cdot$ Mariusz Dyląg $^{2}$
}

Received: 8 January 2020 / Accepted: 23 March 2020 / Published online: 30 March 2020

(c) The Author(s) 2020

\begin{abstract}
Background Fungal infections of the skin, hair, and nails are the largest and most widespread group of all mycoses. Nannizzia nana is a relatively rare etiological factor of dermatomycosis in humans, as it usually affects animals, e.g. pigs and boars. In addition to the zoophilic nature, there are also reports of the geophilic reservoir of this dermatophyte species.

Objective In this study, we present symptomatic infections with $N$. nana aetiology in humans reported recently in Poland. Interestingly, these cases had a non-specific clinical picture and occurred as skin lesions on the neck and foot as well as onychomycosis of the toenails. From the medical history, the patients had no contact with pigs.

Methods Diagnostics of these infections was performed with a combination of classical phenotypic and molecular genomic methods. The genomic diversity of the isolates was determined using the MP-PCR method. In vitro antifungal susceptibility tests against itraconazole, ketoconazole, terbinafine and naftifine hydrochloride were also performed.

Results Nannizzia nana has been identified as an etiological factor of dermatomycosis. Moreover, heterogeneity of the genomes was revealed for the obtained strains. In vitro activities of antifungal agents showed that isolates were susceptible to all tested drugs. The patients were treated with oral terbinafine and topical ketoconazole cream, which led to a complete recovery.

Conclusions In conclusion, the cases studied by us may indicate that the infrequency of $N$. nana infections may not necessarily be related to the low infectivity of this fungal agent, but they are rather associated with misdiagnosis. Furthermore, $N$. nana reservoirs should also be sought in soil.
\end{abstract}

Keywords Nannizzia nana $\cdot$ Onychomycosis $\cdot$ Superficial infection $\cdot$ Diagnostics $\cdot$ Genetic diversity

\section{Introduction}

Dermatophytes are keratinophilic fungi that affect nails, hairs, and skin of humans, warm-blooded animals, and others [1,2]. Approximately, 20-25\% of the global human population is infected with a dermatophyte at least once per lifetime $[3,4]$. About 30 clinically relevant dermatophyte

Sebastian Gnat

sebastian.gnat@up.lublin.pl

1 Department of Veterinary Microbiology, Faculty of Veterinary Medicine, Institute of Biological Bases of Animal Diseases, University of Life Sciences in Lublin, Akademicka 12, 20-033 Lublin, Poland

2 Department of Mycology and Genetics, Faculty of Biological Sciences, Institute of Genetics and Microbiology, University of Wroclaw, Przybyszewskiego 63/77, 51-148 Wroclaw, Poland species are known, but their taxonomy has been controversial because of the incongruence of phenotypic and molecular characters $[5,6]$.

The genus Nannizzia was introduced by Stockdale [7] with Nannizzia incurvata Stockdale 1961 as a type species to accommodate Microsporum-like species producing gymnothecia, which were discovered in 1927 by Nannizzi. Most of the species classified in the genus Nannizzia were described with double nomenclature after finding their heterothallic sexual form $[1,8]$. Currently, for practical reasons and necessity, de Hoog et al. [6] proposed the sexual names as nomenclatural reference with molecular differentiation as the leading classificatory principle. Nannizzia (likewise the genus Arthroderma) is separated as an independent, holomorphic genus located between Trichophyton and the preponderantly zoophilic genus Microsporum [6]. Several species were found to cluster in the well-demarcated Nannizzia group, e.g. N. nana (C.A. Fuentes) Y. Gräser and de 
Hoog (2016) [6], formerly known as Microsporum nanum C.A. Fuentes (1956)[9].

Nannizzia nana is the common cause of ringworm in the pig $[4,10]$. In the 80 s, approximately $27 \%$ of pigs were infected by $N$. nana, since these infections were easily transmitted between animals in the same flock [10]. In recent years, there are scarce reports on the occurrence of infections caused by this dermatophyte species. In 2009, an outbreak of ringworm caused by $N$. nana was reported in sows in Spain [11]. In exceptional cases, infections have been reported in other animals such as dogs, cats, and mice [12-14]. It is also important to underline that this dermatophyte species is usually acquired directly from the soil, rather than from other animal hosts [4, 14]. N. nana is distributed worldwide, but only few cases have been described in humans $[11,12,15]$.

The aim of our study was to carry out diagnostic analysis to confirm species identification of Nannizzia nana isolates. All the strains were isolated from humans with clinical symptoms of dermatomycosis and identified using conventional laboratory methods, ITS sequencing, MP-PCR differentiation, and antifungal susceptibility testing.

\section{Materials and methods}

\section{Dermatophyte strains}

The dermatophyte isolates used in this study were obtained from three clinical cases. The first was a 28 -year-old male resident of an urban area in central Poland, who attended dermatological consultation due to 20-day localized superficial skin lesion on the neck (Fig. 1a). The clinical lesion was erythematous and scaly, sharply demarcated, with active borders, and although no chronic scratching marks were seen, the patient reported itching. The man had not suffered from superficial mycosis earlier and had no other chronic diseases. As shown by his medical history, the patient does not breed pets and has not been in contact with objects of animal hygiene recently. However, the man had contact with the soil while carrying out works in the allotment garden.

The second case was a 41-year-old female resident of a rural area in eastern Poland. The patient came for dermatological consultation with 1-year long-standing skin lesions. Clinical changes included erythematous squamous plaques on both feet (Fig. 1b). The woman reported severe itching with a burning sensation. The patient used ointment with terbinafine for 2 months before seeking medical advice. The medical history indicated that she did not suffer from other illnesses and did not take any medicines on a longterm basis. The woman professionally deals with cultivation of the field and growing vegetables in a small farm. The woman is in constant contact with animals, mainly cattle and two dogs.

The third case was diagnosed in a 75-year-old female resident from a rural area of eastern Poland, who asked for medical advice because of recurrent onychomycosis (Fig. 1c). The lesions occurred for the first time about 7 months earlier. Clinical changes affected the nail plate, which was grey, matte, and crumbling. During this period, the patient did not use any antifungal agents. The woman suffers from geriatric problems and is under the supervision of an internist. As shown by the interview, the woman is an owner of three cats who are often away from the homestead.

All three patients received treatment with terbinafine orally at a dose of $250 \mathrm{mg} /$ day and topically with ketoconazole $2 \%$ cream applied twice daily to the affected areas. In the case of the man, the treatment lasted 20 days; in the second case described above, 40-day treatment was administered. The woman with onychomycosis was advised to remove the nails and was treated for 6 weeks. In all the three cases, the treatment was fully successful, with complete clearance of the lesions. None of the patients experienced a relapse during the next few months of the follow-up period. The eradication of the infection in the case of all the patients was evidenced by negative direct microscopy and culture.
Fig. 1 Changes in human skin during infection with Nannizzia nana (camera: Nikon D3300, lens Nikon 18-105 mm VR). a In the man; $\mathbf{b}$ in the 41-year-old woman; $\mathbf{c}$ in the 75 -year-old woman
A

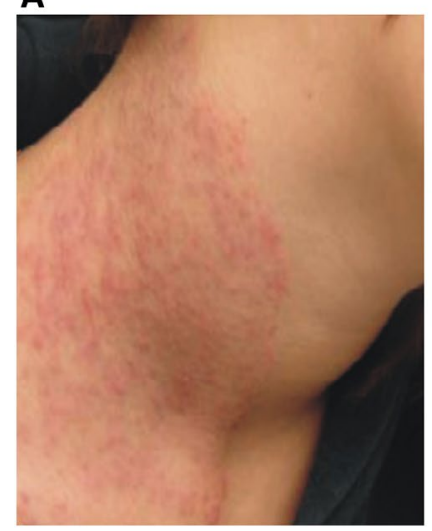

B

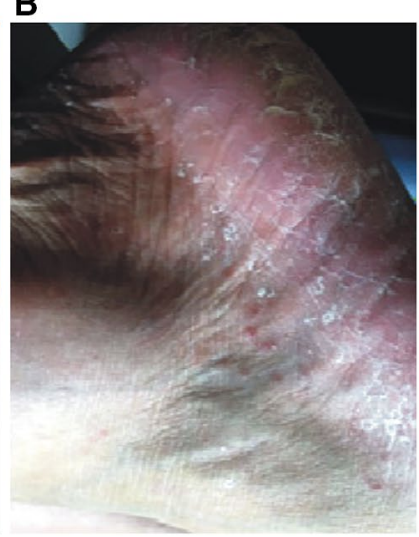

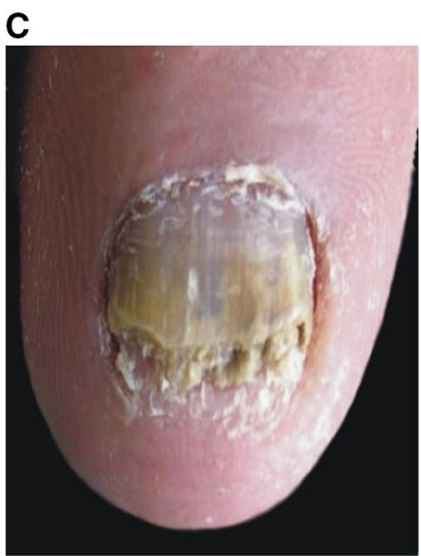




\section{Laboratory diagnostic procedures}

Species identification of the isolates were performed with a combination of classical phenotypic and molecular genomic methods as described previously by Gnat et al. [16, 17]. In brief, direct examination of the clinical material collected from the patients, i.e. skin and nail scrapings treated with dimethyl sulphoxide (DMSO) and $10 \% \mathrm{KOH}$, was performed. Each time the diagnostic material was inoculated simultaneously onto Sabouraud's glucose agar (Becton Dickinson, New Jersey, USA) at $37{ }^{\circ} \mathrm{C}$ for 3 weeks and Dermatophyte Test Medium (BioMaxima, Lublin, Poland) at $28{ }^{\circ} \mathrm{C}$ for 2 weeks. The fungi were identified based on colony texture, production of typical mycelium structures, especially species-specific macroconidia, and positive reaction observed on the DTM. Genomic DNA was isolated from the cultures of dermatophytes according to the phenol-chloroform method [18]. Molecular identification was performed by Internal Transcribed Spacer (ITS) region amplification and PCR product sequencing with primers ITS1/ITS4 [19]. The melting profile PCR (MP-PCR) method was used to determine the genomic differentiation of the isolates [20].

\section{Antifungal susceptibility testing}

Since a number of recent reports have revealed emergent drug resistance among clinical isolates of dermatophytes, in vitro antifungal susceptibility tests against itraconazole, ketoconazole, terbinafine and naftifine hydrochloride were performed in this study. All the compounds used in the present experiments were, if not stated otherwise, purchased from Sigma-Aldrich (Missouri, USA) and were of analytical grade. Susceptibility assays were performed according to the Clinical and Laboratory Standard Institute (CLSI) M38-A2 document [21]. All analyses were made in triplicate.

\section{Results}

The direct analysis of the material revealed the presence of arthrospores in the samples collected from the skin lesions. The macro- and micromorphology of the colonies and mycelial structures obtained from the clinical material of the three patients were almost identical and suggested that all the strains belong to one specific species (Fig. 2). After 3 weeks of incubation, the colonies were gently fluffy and cream to beige in colour with a suede-like texture; reddishbrown pigmentation was present on the reverse side of the colony. Microscopic examination of the culture-derived preparations stained with lactophenol cotton blue (LPCB) revealed short pyriform thick-walled macroconidia with one to three (mostly two) cells. Based on the morphology and classical phenotypic methods, all the three dermatophyte isolates were identified as Nannizzia nana. A comparative analysis of ITS sequences (PCR products obtained with ITS1 and ITS4 primers) of the isolated strains with the sequences of reference strains available in the NCBI (National Center for Biotechnology Information) database revealed a $99 \%$ similarity to Nannizzia nana CBS 314.54 (Table 1). The MP-PCR showed genomic diversity of the examined dermatophyte strains. The examination based on agarose gel electrophoregram indicated two different types of profile: one characteristic for the strain isolated from the man and the other one specific for the clinical strains obtained from both women (Fig. 3). Screening of the material taken from animals with which the women had contact showed no presence of the dermatophytes.

In vitro activities of antifungal agents that can potentially be used either orally or topically showed that all the isolates tested were susceptible to itraconazole, ketoconazole, terbinafine, and naftifine hydrochloride (Table 1). Minimal inhibitory concentration (MIC) values among the isolates varied from 0.125 to $0.5 \mu \mathrm{g} / \mathrm{ml}$. Geometric means of the minimal inhibitory concentration of ketoconazole $(0.167 \mu \mathrm{g} /$ $\mathrm{ml})$ and terbinafine $(0.208 \mu \mathrm{g} / \mathrm{ml})$ were the lowest for the examined isolates, indicating that these drugs were the most potent in the therapy of each of the cases described in this work. Nonetheless, the mean MICs of the antifungal drugs did not exhibit statistically significant differences between each other $(p>0.05)$.

\section{Discussion}

Nannizzia nana, reported previously as Microsporum nanum, was first described in 1954 by Fuentes et al. [9] in Cuba as the aetiological agent of tinea capitis in a child, identified as a dwarf form of Microsporum gypseum [22]. Swine are the natural host for this dermatophyte [22]. $N$. nana is regarded as a low-virulence aetiological agent; it was even thought to be part of pigs' skin microbiota [23]. The majority of human patients with dermatomycosis caused by $N$. nana was linked with direct daily or long-lasting contact with these animals on pig farms [15, 22, 24, 25].

Clinical pictures of $N$. nana infections in humans are related mainly to tinea corporis with a characteristic ring shape with an erythematous, scaly, circinate plaque and, rarely, dry or inflammatory tinea capitis [11]. Occasionally, lesions on the skin may suggest Microsporum canis infection [15]. Bonifaz et al. [22] described two severe cases of $N$. nana infection in siblings in 2019 , in which an 8-yearold boy was affected by mycosis of the scalp developing as a pseudoalopecic tumour lesion and a 6-year old girl, his sister, presented with dermatomycosis characterized by multiple erythematous-scaly plaques on her face, trunk, and arms. Dermatomycosis among children in Mexico is closely 

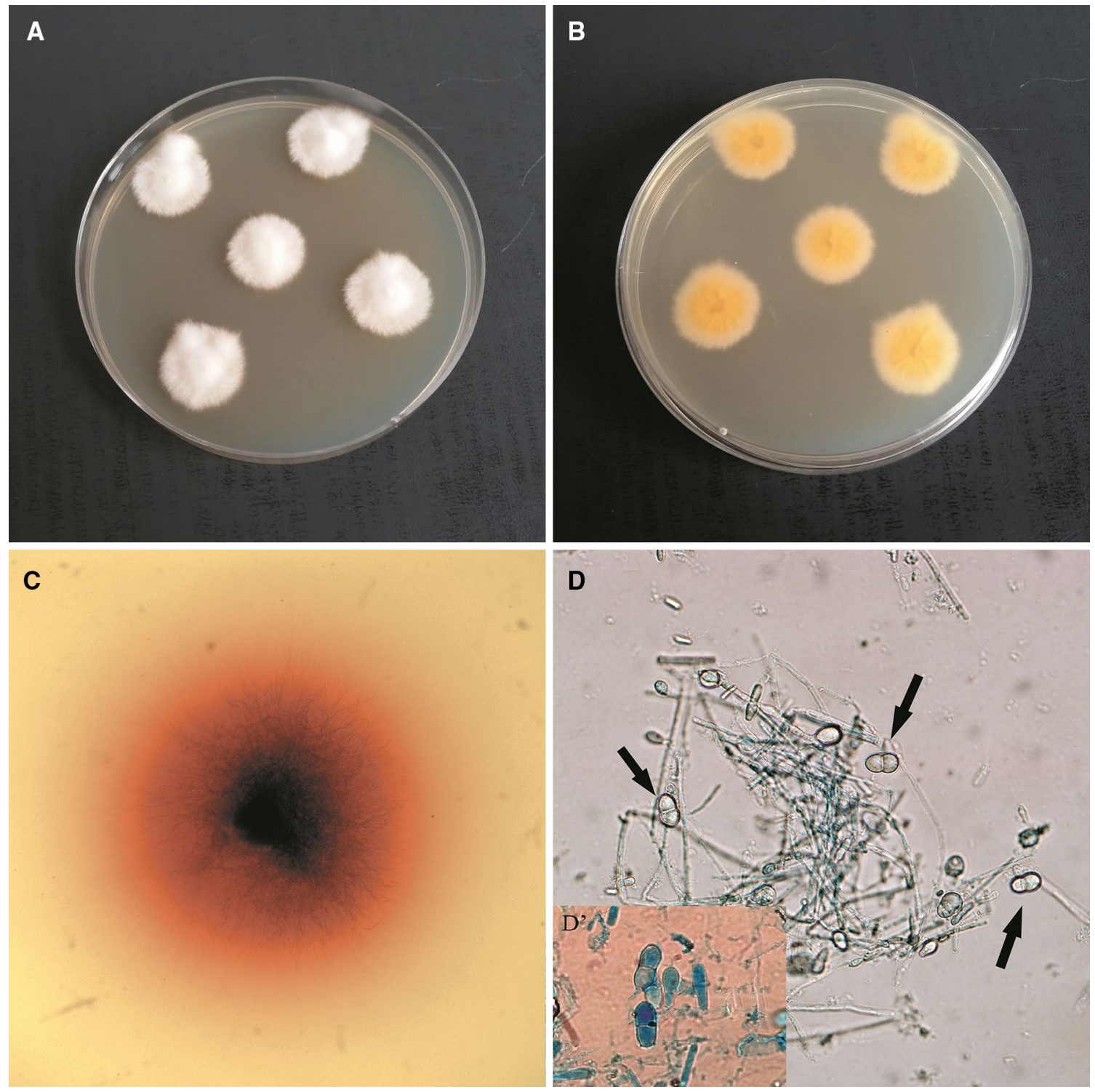

Fig. 2 Micro- and macroscopic morphology of isolated dermatophytes, Nikon Coolpix YS100). a Obverse of Nannizzia nana isolate; b reverse of Nannizzia nana isolate; c positive reaction on Dermato-

phyte Test Medium; d micromorphology, arrows indicate characteristic macroconidia (magnification 400x); d' macroconidia stained with lactophenol blue (magnification 1000×)

Table 1 Isolates of dermatophytes with description

\begin{tabular}{|c|c|c|c|c|c|c|c|c|}
\hline \multirow[t]{2}{*}{ Isolates } & \multirow[t]{2}{*}{ Host } & \multirow{2}{*}{$\begin{array}{l}\text { Loca- } \\
\text { tion of } \\
\text { changes }\end{array}$} & \multirow{2}{*}{$\begin{array}{l}\text { Accession } \\
\text { numbers of ITS } \\
\text { sequences }\end{array}$} & \multirow{2}{*}{$\begin{array}{l}\text { Identification consistent with the NCBI } \\
\text { database }\end{array}$} & \multicolumn{4}{|c|}{ Drug sensitivity, MIC values $[\mu \mathrm{g} / \mathrm{ml}]$} \\
\hline & & & & & Itraconazole & Ketoconazole & Terbinafine & Naftifine \\
\hline $\mathrm{NN}$ & Human & Neck & MN307390 & \multirow{3}{*}{$\begin{array}{l}\text { Nannizzia nana CBS365.53 (accession } \\
\text { number NR154982.1) } \\
99 \%\end{array}$} & 0.5 & 0.125 & 0.125 & 0.25 \\
\hline NN1 & Human & Foot & MN307391 & & 0.25 & 0.125 & 0.25 & 0.5 \\
\hline NN2 & Human & Nail & MN307392 & & 0.5 & 0.25 & 0.25 & 0.5 \\
\hline
\end{tabular}

NCBI National Center for Biotechnology Information, MIC minimal inhibitory concentration 


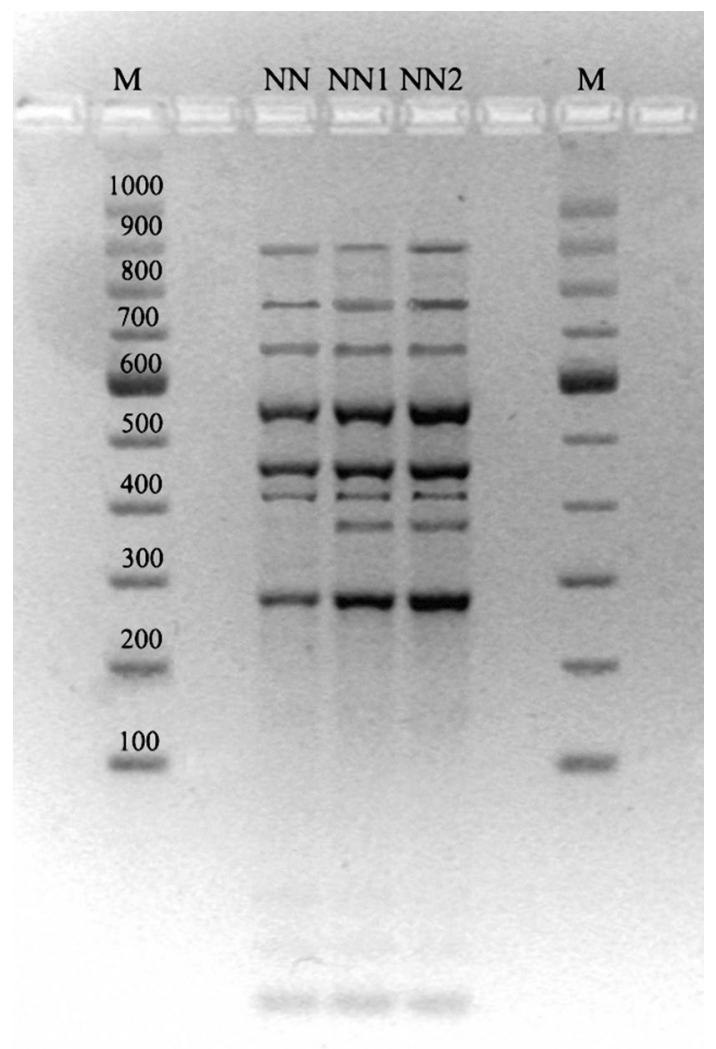

Fig. 3 Electrophoretic profile obtained with MP-PCR fingerprinting methods in $3 \%$ agarose gel. M-Molecular weight marker A\&A Biotechnology (100-1000 bp), NN-strain isolated from the man, NN1-strain isolated from the 41-year-old woman, NN2-strain isolated from the 75-year-old woman

related to the coexistence with pigs on the same farm [22]. The authors of these publications do not consider other sources of $N$. nana infection in these two cases.

Our study reveals, however, completely different characteristics of this dermatophyte species. The three reported cases occurred in Poland in the summer months of 2018 in patients living at a distance of about $150 \mathrm{kms}$ from each other. None of them reported contact with pigs. In addition, the location of the clinical lesions, which covered the edge of the foot and toenails in two of the three described cases, did not indicate a zoonotic origin of the dermatomycosis and might suggest rather a geophilic source. In the literature, there are also reports on exceptional cases of tinea pedis and onychomycosis caused by $N$. nana [26, 27]. Furthermore, $N$. nana reservoirs should also be sought in soil, and the information on the dual nature of this dermatophyte, both zoophilic and geophilic, seems to be relevant [28].

Interestingly, genotyping of clinical isolates by MP-PCR showed no homology of the strains. Two different types of profile were obtained: the first one characteristic for the male patient and the other one determined for the two female patients. Finding causal links between this genomic similarity and infection epidemiology can only be speculative, but it is important that methods for determining genomic diversity can also be used for $N$. nana. There are no reports in the literature about genomic polymorphism in this species of dermatophyte. In many outbreaks of dermatomycoses of different aetiology, e.g. caused by Microsporum canis [17, 29, 30] or Trichophyton verrucosum [20], genotyping methods have been found greatly suitable in searching for the most probable sources of infection and determining pathogen transmission pathways. Comprehensive analysis on this issue for $N$. nana infections is necessary to reach definitive findings.

Unfortunately, in the literature, there are only few reports on the minimal inhibitory concentration (MIC) values of $N$. nana. Hence, antifungal therapy is usually chosen based on the response observed when treating other dermatomycoses caused by fungi of the genus Microsporum [22, 31]. In our study, the in vitro susceptibility to the main antifungals indicates that $N$. nana is highly sensitive to itraconazole, ketoconazole, terbinafine, and naftifine hydrochloride. Wildfeuer et al. [32] observed the following MICs for $N$. nana (Microsporum nanum in the original publication): griseofulvin $3.1 \mu \mathrm{g} / \mathrm{ml}$; voriconazole and itraconazole $0.78 \mu \mathrm{g} / \mathrm{ml}$, and ketoconazole $0.2 \mu \mathrm{g} / \mathrm{ml}$. In turn, in their case report of dermatomycoses in the siblings, Bonifaz et al. [22] noted that $N$. nana was sensitive to miconazole, clotrimazole, and ketoconazole without specifying the inhibitory concentration range of these drugs. Furthermore, there are no precise data in the literature about $N$. nana sensitivity toward terbinafine and naftifine hydrochloride. Noteworthy, these studies include only few strains. This issue requires more extensive research and deeper discussion.

Dermatomycoses are still often misunderstood and underestimated. The infrequency of infections caused by many species of dermatophytes, including $N$. nana, may not be related to the low infectivity of this fungal agent, but rather to misdiagnosis. Differential diagnostics based on classical and molecular methods is equally important as the knowledge of the sources and reservoirs of dermatophytes. As emphasised by many experts, these are the keys to proper therapy.

\section{Compliance with ethical standards}

Conflict of interest The authors declare that they have no conflict of interest.

Ethical approval All procedures performed in studies involving human participants were in accordance with the ethical standards and with the 1964 Helsinki Declaration and its later amendments or comparable ethical standards.

Informed consent Informed consents have been obtained. No identification data are disclosed. 
Open Access This article is licensed under a Creative Commons Attribution 4.0 International License, which permits use, sharing, adaptation, distribution and reproduction in any medium or format, as long as you give appropriate credit to the original author(s) and the source, provide a link to the Creative Commons licence, and indicate if changes were made. The images or other third party material in this article are included in the article's Creative Commons licence, unless indicated otherwise in a credit line to the material. If material is not included in the article's Creative Commons licence and your intended use is not permitted by statutory regulation or exceeds the permitted use, you will need to obtain permission directly from the copyright holder. To view a copy of this licence, visit http://creativecommons.org/licenses/by/4.0/.

\section{References}

1. Gnat S, Nowakiewicz A, Zięba P. Taxonomy of dermatophytesthe classification systems may change but the identification problems remain the same. Adv Microbiol. 2019;58:49-58. https://doi. org/10.21307/PM-2019.58.1.049.

2. Weitzman I, Summerbell RC. The dermatophytes. Clin Microbiol Rev. 1995;8:240-59.

3. Havlickova B, Czaika VA, Friedrich M. Epidemiological trends in skin mycoses worldwide. Mycoses. 2008;51:2-15. https://doi. org/10.1111/j.1439-0507.2008.01606.x.

4. Gnat S, Nowakiewicz A, Łagowski D, Zięba P. Host- and pathogen-dependent susceptibility and predisposition to dermatophytosis. J Med Microbiol. 2019;68:823-36. https://doi.org/10.1099/ jmm.0.000982.

5. Graser Y, Scott J, Summerbell R. The new species concept in dermatophytes - a polyphasic approach. Mycopathologia. 2008;166:239-56. https://doi.org/10.1007/s11046-008-9099-y.

6. de Hoog GS, Dukik K, Monod M, et al. Toward a novel multilocus phylogenetic taxonomy for the dermatophytes. Mycopathologia. 2017;182:5-31. https://doi.org/10.1007/s11046-016-0073-9.

7. Stockdale PM. Nannizzia incurvata gen. nov., sp. nov., a perfect state of Microsporum gypseum (Bodin) Guiart et Grigorakis. Med Mycol. 1962;1:41-8. https://doi.org/10.1080/003621762851901 01.

8. Dukik K, Sybren de Hoog G, Benjamin Stielow J, et al. Molecular and phenotypic characterization of Nannizzia (Arthrodermataceae). Mycopathologia. 2019. https://doi.org/10.1007/s1104 6-019-00336-9.

9. Fuentes CA. A new species of Microsporum. Mycologia. 1956;48:613-4. https://doi.org/10.2307/3755345.

10. Roller JA, Ulf Westblom T. Microsporum nanum infection in hog farmers. J Am Acad Dermatol. 1986;15:935-9. https://doi. org/10.1016/S0190-9622(86)70252-1.

11. García-Sánchez A, Bazán J, de Mendoza JH, et al. Outbreak of ringworm in a traditional Iberian pig farm in Spain. Mycoses. 2011;54:179-81. https://doi.org/10.1111/j.1439-0507.2009.01776 .x.

12. Ilhan Z, Karaca M, Ekin IH, et al. Detection of seasonal asymptomatic dermatophytes in van cats. Braz J Microb. 2016;47:225-30. https://doi.org/10.1016/j.bjm.2015.11.027.

13. Rebollo N, López-Barcenas AP, Arenas R. Tinea Capitis. Actas Dermo-Sifiliográficas (English Ed). 2008;99:91-100. https://doi. org/10.1016/S1578-2190(08)70208-7.

14. Łagowski D, Gnat S, Nowakiewicz A, et al. The prevalence of symptomatic dermatophytoses in dogs and cats and the pathomechanism of dermatophyte infections. Adv Microbiol. 2019;58:165-76. https://doi.org/10.21307/PM-2019.58.2.165.

15. Śpiewak R, Szostak W. Zoophilic and geophilic dermatophytoses among farmers and non-farmers in Eastern Poland. Ann Agric Environ Med. 2000;7:125-9.
16. Gnat S, Łagowski D, Nowakiewicz A, Zięba P. Phenotypic characterization of enzymatic activity of clinical dermatophyte isolates from animals with and without skin lesions and humans. J Appl Microbiol. 2018;125:700-9. https://doi.org/10.1111/jam.13921.

17. Gnat S, Łagowski D, Nowakiewicz A, Zięba P. Tinea corporis by Microsporum canis in mycological laboratory staff: unexpected results of epidemiological investigation. Mycoses. 2018;61:94553. https://doi.org/10.1111/myc.12832.

18. Gnat S, Nowakiewicz A, Ziółkowska G, et al. Evaluation of growth conditions and DNA extraction techniques used in the molecular analysis of dermatophytes. J Appl Microbiol. 2017;122:1368-79. https://doi.org/10.1111/jam.13427.

19. White TTJT, Bruns T, Lee S, Taylor J. Amplification and direct sequencing of fungal ribosomal RNA genes for phylogenetics. In: Innis M, Gelfand D, Shinsky J, White T, editors. PCR protocols: a guide to methods and applications. San Diego: Academic Press; 1990. p. 315-322.

20. Gnat S, Łagowski D, Nowakiewicz A, et al. Infection of Trichophyton verrucosum in cattle breeders, Poland: a 40-year retrospective study on the genomic variability of strains. Mycoses. 2018;61:681-90. https://doi.org/10.1111/myc.12791.

21. CLSI (2008) Reference method for broth dilution antifungal susceptibility testing of filamentous fungi; Approved Standard, 2nd edn. Clinical and Laboratory Standards Institute, 940 West Valley Road, Wayne, $\mathrm{Pa}$.

22. Bonifaz A, Córdoba-García B, Simancas-Llanos T, et al. Dermatophytosis caused by Nannizzia nana in two siblings. Rev Iberoam Micol. 2019;36:30-3. https://doi.org/10.1016/j.riam.2018.02.003.

23. Zhu WY, Xia MY, Huang L, et al. Electron microscopic observation on infected hairs of kerion caused by Microsporum nanum. Int J Dermatol. 1987;26:641-4. https://doi. org/10.1111/j.1365-4362.1987.tb02270.x.

24. Fuentes CA, Aboulafia R, Vidal RJ. A dwarf form of Microsporum gypseum. J Invest Dermatol. 1954;23:51-61. https://doi. org/10.1038/jid.1954.82.

25. Ranganathan S, Menon T, Balajee SA. Isolation of Microsporum nanum from a patient with tinea corporis in Madras, India. Mycoses. 1997;40:229-30.

26. Martínez E, Ameen M, Tejada D, Arenas R. Microsporum spp. onychomycosis: disease presentation, risk factors and treatment responses in an urban population. Braz J Infect Dis. 2014;18:1816. https://doi.org/10.1016/j.bjid.2013.08.005.

27. Moutaj R, Soraa N, Laissaoui K, Jana M. Une teigne humaine rare à Microsporum nanum: à propos d'une observation marocaine. J Mycol Med. 2007;17:65-9. https://doi.org/10.1016/j.mycme d.2006.08.005.

28. Rebell G, Taplin D. Dermatophytes: their recognition and identification. Coral Gables: University of Miami Press; 1970.

29. Dobrowolska A, Dębska J, Kozłowska M, Stączek P. Strains differentiation of Microsporum canis by RAPD analysis using (GACA)4 and (ACA)5 primers. Polish J Microbiol. 2011;60:145-8.

30. Brilhante RSN, Rocha MFG, Cordeiro RA, et al. Phenotypical and molecular characterization of Microsporum canis strains in north-east Brazil. J Appl Microbiol. 2005;99:776-82. https://doi. org/10.1111/j.1365-2672.2005.02685.x.

31. John AM, Schwartz RA, Janniger CK. The kerion: an angry tinea capitis. Int J Dermatol. 2018;57:3-9. https://doi.org/10.1111/ ijd.13423.

32. Wildfeuer A, Seidl HP, Paule I, Haberreiter A. In vitro evaluation of voriconazole against clinical isolates of yeasts, moulds and dermatophytes in comparison with itraconazole, ketoconazole, amphotericin B and griseofulvin. Mycoses. 1998;41:309-19. 